\title{
Utility of Computed Tomography in a Differential Diagnosis for the Patients with an Initial Diagnosis of Chronic Obstructive Pulmonary Disease Exacerbation
}

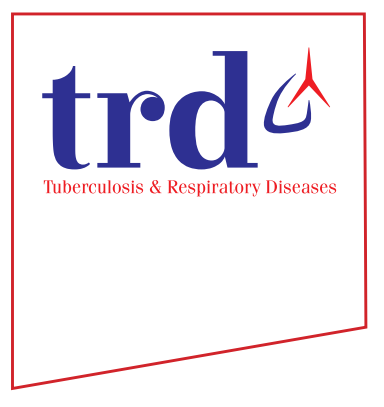

Hyung Jun Park, M.D. ${ }^{1}{ }^{(D}$, Soo Han Kim, M.D. ${ }^{1}$, Ho-Cheol Kim, M.D. ${ }^{1}$, Bo Young Lee, M.D., Ph.D. ${ }^{1}$, Sei Won Lee, M.D., Ph.D. ${ }^{1}$, Jae Seung Lee, M.D., Ph.D. ${ }^{1}$, Sang-Do Lee, M.D., Ph.D. ${ }^{1}$, Joon Beom Seo, M.D., Ph.D. ${ }^{\circledR i D}$ and Yeon-Mok Oh, M.D., Ph.D. ${ }^{1}$ (iD

Departments of ${ }^{1}$ Pulmonary and Critical Care Medicine and ${ }^{2}$ Radiology, Asan Medical Center, University of Ulsan College of Medicine, Seoul, Korea

Background: The utility of computed tomography (CT) in the differential diagnosis of patients with chronic obstructive pulmonary disease (COPD) exacerbation remains uncertain. However, due to the low cost associated with CT scan along with the impact of Koreas' health insurance system, there has been a rise in the number of CT scans in the patients with initial diagnosis of COPD exacerbations. Therefore, the utility of CT in the differential diagnosis was investigated to determine whether performing CT scans affect the clinical outcomes of the patients with an initial diagnosis of COPD exacerbation.

Methods: This study involved 202 COPD patients hospitalized with an initial diagnosis of COPD exacerbation. We evaluated the change in diagnosis or treatment after performing a CT scan, and compared the clinical outcomes of patient groups with vs. without performing CT (non-CT group vs. CT group).

Results: After performing CT, the diagnosis was changed for two (3.0\%) while additional diagnoses were made for 27 of the 64 patients $(42.1 \%)$. However, the treatment changed for only one (1.5\%), and six patients $(9.3 \%)$ received supplementary medication. There were no difference in the median length of hospital stay (8 [6-13] days vs. 8 [6-12] days, $\mathrm{p}=0.786)$ and intensive care unit care $(14[10.1 \%]$ vs. $11[16.7 \%], \mathrm{p}=0.236)$ between the CT and non-CT groups, respectively. These findings remained consistent even after the propensity score matching.

Conclusion: Utility of CT in patients with acute COPD exacerbation might not be helpful; therefore, we do not recommend chest CT scan as a routine initial diagnostic tool.

Keywords: Disease Exacerbation; Pulmonary Disease, Chronic Obstructive; Hospitalization; Tomography, X-Ray Computed

Address for correspondence: Yeon-Mok Oh, M.D., Ph.D.

Department of Pulmonary and Critical Care Medicine, Asan Medical Center, University of Ulsan College of Medicine, 88 Olympic-ro 43-gil, Songpa-gu, Seoul 05505, Korea

Phone: 82-2-3010-3136, Fax: 82-2-3010-4650, E-mail: ymoh55@amc.seoul.kr

Address for co-correspondence: Joon Beom Seo, M.D., Ph.D.

Department of Radiology, Asan Medical Center, University of Ulsan College of Medicine, 88 Olympic-ro 43-gil, Songpa-gu, Seoul 05505, Korea

Phone: 82-2-3010-4383, Fax: 82-2-476-0090, E-mail: seojb@amc.seoul.kr

Received: Nov. 22, 2018, Revised: Jan. 24, 2019, Accepted: Feb. 22, 2019, Published online: May. 31, 2019

(a) It is identical to the Creative Commons Attribution Non-Commercial License (http://creativecommons.org/licenses/by-nc/4.0/). 


\section{Introduction}

Chronic obstructive pulmonary disease (COPD) is one of the leading causes of morbidity and mortality worldwide ${ }^{1}$. During the disease course, COPD patients can experience an exacerbation, which may necessitate hospitalization, increase subsequent risk of future exacerbations, and even lead to death particularly in cases requiring hospitalization ${ }^{1,2}$. During a COPD exacerbation, patients experience dyspnea, cough, and sputum, which may lead to a change in medication ${ }^{3}$. These symptoms may occur both during a COPD exacerbation and with other diseases such as pneumonia, pneumothorax, pulmonary embolism, arrhythmia, and congestive heart failure ${ }^{1}$. Therefore, chest X-ray and electrocardiography (ECG) has been routinely performed in the emergency department to check for these diseases.

Computed tomography (CT) may have a higher sensitivity to detect these lung diseases than conventional chest X-ray ${ }^{4-6}$. The CT scans is used to detect unnoticed finding in chest Xray and to explain for other cause of desaturation in COPD exacerbation, especially for the ones severe enough to warrant hospitalization. The cost of a CT scan is relatively inexpensive in Korea compared to other countries. As a result, the number of CT scans for patients with an initial diagnosis of COPD exacerbation has increased. However, no study has yet proven that chest CT has higher diagnostic value to find these lung diseases compared to chest X-ray and whether it could affect clinical outcomes such as hospital stay and intensive care unit (ICU) care.

In this study, we investigated the utility of CT in diagnostic change or an additional diagnosis for patients who were hospitalized with an initial diagnosis of COPD exacerbation, and showed whether performing CT may affect treatment or clinical outcomes.

\section{Materials and Methods}

\section{Study design and subjects}

In this retrospective cohort study, we included COPD patients who were hospitalized with an initial diagnosis of a COPD exacerbation at the Asan Medical Center, a tertiary hospital located in Seoul, South Korea, from January 2010 to December 2012. COPD exacerbation was defined as aggravated respiratory symptoms in COPD patients and excluded patients in whom another disease, such as pneumonia, pneumothorax, interstitial lung disease, and arrhythmia, were diagnosed by an initial chest X-ray or ECG. In these patients, we evaluated the change in the diagnosis or treatment following the chest CT scan. We also compared the clinical outcomes, including the length of hospital stay, ICU care and number of hospital deaths between patients who underwent CT (the CT group) and those who did not (the non-CT group). The decision to perform CT was at the discretion of the physician who first evaluated the COPD patient in the emergency department (ER) or by the respiratory specialist who was in charge of the patient during hospitalization.

The included patients were hospitalized both from the ER and the outpatient clinic. The initial physician diagnosis of a COPD exacerbation was made by an ER physician or a respiratory specialist. Irrespective of cigarette smoking history, we included patients whose stable-state spirometry revealed a ratio of the forced expiratory volume in 1 second $\left(\mathrm{FEV}_{1}\right)$ to forced vital capacity of less than 0.70 . We excluded definite asthma patients, however, included patients with bronchodilator response positive. It might include patients as asthma and COPD overlap syndrome.

We also excluded patients whose medical records were incomplete for the evaluation of clinical outcomes, the length of hospital stay, hospital death, and ICU care. Additionally, of the patients who underwent a chest CT, we excluded any patients who underwent a chest CT before the initial chest X-ray or 72 hours after hospitalization. We also excluded patients who underwent a chest CT at a hospital or clinic other than our medical center.

\section{Ethics committee approval}

This study was approved by the ethics committee of the Asan Medical Center (approval number, 2014-0907), and the need to obtain informed consent was waived due to the retrospective observational nature of the study.

\section{CT protocol}

Chest CT was performed by using 16- or 64-detector row equipment (Somatom Sensation 16; Siemens Medical Solutions, Forchheim, Germany) and LightSpeed VCT (GE Medical, Milwaukee, WI, USA). For the 16-detector row scanner, the parameters were $120 \mathrm{kV}$ and 100 effective $\mathrm{mA}$ with dose modulation. For the 64-detector row scanner, the parameters were $120 \mathrm{kV}$ and $100-400 \mathrm{~mA}$ with dose modulation. CT was performed with contrast enhancement for 40 patients and without contrast enhancement for 24 patients. Low-dose chest CT was performed two patients in contrast-enhanced chest CT group. For contrast-enhanced CT, images were obtained after the intravenous administration of $100 \mathrm{~mL}$ of iopromide with $300 \mathrm{mg} / \mathrm{mL}$ of iodine (Ultravist 300; Bayer Pharma, Berlin, Germany) at a rate of $2.5 \mathrm{~mL} / \mathrm{sec}$ using a power injector. CT was performed with a 50 -second delay.

\section{Clinical outcomes and statistical analysis}

The baseline characteristics of the continuous variables were compared using Student's t test or Mann-Whitney U test 
according to normality. The categorical variables were compared using a chi-square test while some categorical variables less than five were analyzed by Fisher exact test.

We evaluated the relationship between CT scan and the length of hospital stay by using a multiple linear regression analysis with an adjustment for the following covariates: age, sex, $\mathrm{FEV}_{1}$, the initial concentration of $\mathrm{O}_{2}$ supply, body mass index, history of hospitalization due to a COPD exacerbation in the previous year, baseline modified Medical Research Council (mMRC) dyspnea scale, increased or purulent sputum, and the initial arterial blood gases of oxygen and carbon dioxide. In multiple linear regression, we chose the covariates through backward method which exclude covariate p-value above 0.2 . But we included CT scan as covariate to determine relationship with CT scan and length of hospital stay. To overcome the design of retrospective study, we performed propensity score matching to normalize baseline characteristics both CT group and non-CT group.

Statistical analyses were performed using SPSS software version 23.0 (IBM Corp., Armonk, NY, USA). p $<0.05$ was considered to indicate a statistically significant difference.

\section{Results}

\section{Baseline characteristics}

After applying the inclusion/exclusion criteria to 281 patients with an initial primary diagnosis of a COPD exacerbation, 54 were excluded (Figure 1). Another 25 who underwent a chest CT were excluded because they underwent CT scan at another hospital $(\mathrm{n}=19)$ or had the CT scan before the chest X-ray or 72 hours after hospitalization $(\mathrm{n}=6)$. Among the included 202 patients, 64 were in the CT group and 138 in the non-CT group. Table 1 represents that the patients were pre- dominantly males, and the mean age was similar between the two groups. The non-CT group appeared to have lower lung function. There was no significant difference of the presence of bronchodilator response in two groups (Supplementary Table S1). All other characteristics were similar between the two groups.

\section{Role of chest CT in a diagnostic change or in an additional diagnosis of COPD exacerbation}

After the chest CT, the diagnosis was changed for two of 64 patients which was represented Table 2. One was from COPD exacerbation to pulmonary embolism $(n=1)$ and the other one was to progression of lung cancer $(n=1)$. Due to the change in diagnosis, anticoagulation was started for the patient with the pulmonary embolism. The other patient with lung cancer progression was treated as for COPD exacerbation without any further treatment for the lung cancer.

Twenty-seven patients were revealed to have an additional diagnosis, including pneumonic infiltration in 21 (32.8\%). These pulmonary infiltrations were in small extent which are not obvious in chest X-ray but conspicuous in CT scan. In four of these 21 patients (19\%), antibiotics were started after the CT, but the other 17 were already being treated with antibiotics for a COPD exacerbation before the CT. Among the 21 patients with pneumonic infiltration, 16 patients continued systemic corticosteroid; one patient discontinued systemic corticosteroid after detecting pneumonic infiltration by chest CT. One patient with pleural effusion was treated with diuretics and nitrate for heart failure. One patient with pericardial effusion was followed up with observation because the pericardial effusion was inaccessible to drainage by pericardiocentesis due to loculation. One patient with pulmonary edema also has pulmonary artery enlargement at exacerbation of COPD. And, the patient was confirmed pulmonary hy-

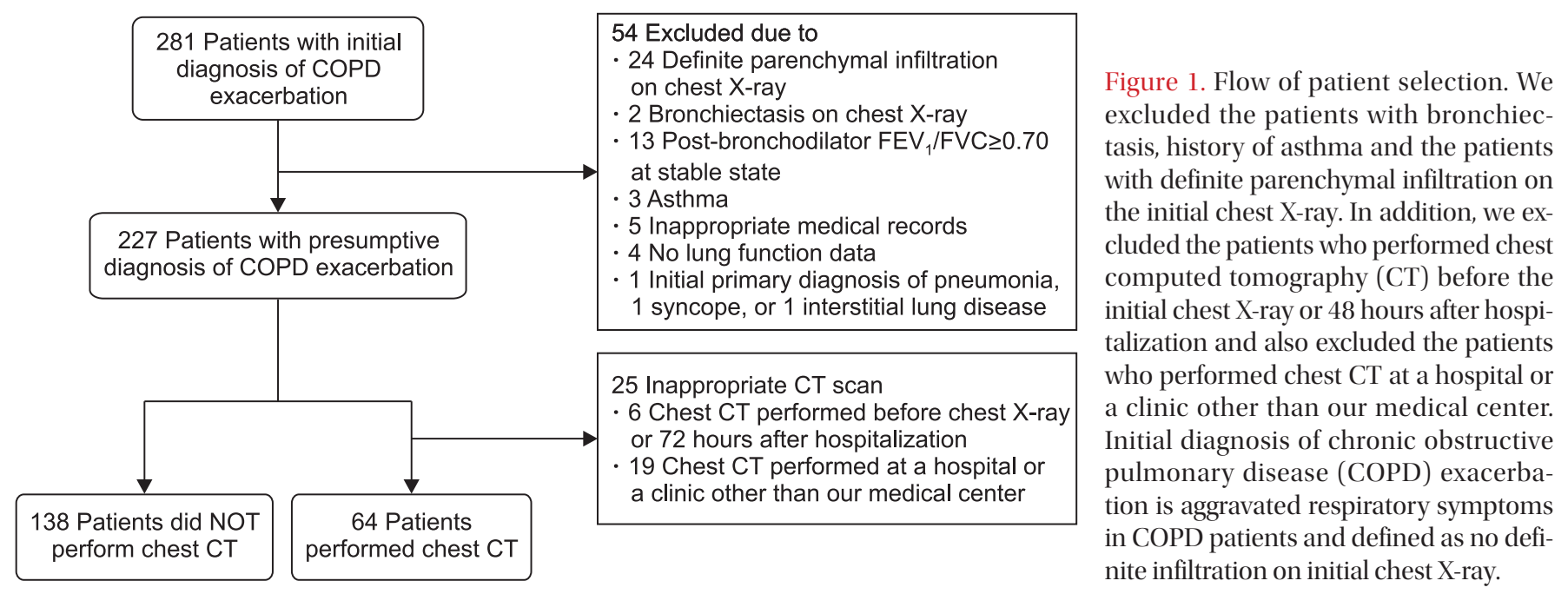


Table 1. Baseline patients' characteristics

\begin{tabular}{|c|c|c|c|c|c|c|}
\hline \multirow[b]{2}{*}{ Characteristic } & \multicolumn{3}{|c|}{ Unmatched group } & \multicolumn{3}{|c|}{ Matched group* } \\
\hline & $\begin{array}{l}\text { Non-CT group } \\
\quad(n=138)\end{array}$ & $\begin{array}{c}\text { CT group } \\
(n=64)\end{array}$ & p-value & $\begin{array}{l}\text { Non-CT group } \\
\quad(n=64)\end{array}$ & $\begin{array}{c}\text { CT group } \\
(n=64)\end{array}$ & p-value \\
\hline Male sex, n (\%) & $120(87.0)$ & $52(81.2)$ & 0.396 & $55(85.9)$ & $52(81.2)$ & 0.633 \\
\hline Mean age, yr & $72(67.0-76.0)$ & $73(67.5-77.5)$ & 0.277 & $71.5(67.0-78.0)$ & $73.0(67.5-77.5)$ & 0.518 \\
\hline $\begin{array}{l}\text { Smoking status } \\
\text { (never/ex-smoker/current), \% }\end{array}$ & $23 / 56 / 21$ & $23 / 56 / 20$ & 0.993 & $22 / 58 / 20$ & $23 / 56 / 20$ & 0.976 \\
\hline $\begin{array}{l}\text { Pre-bronchodilator } \mathrm{FEV}_{1}, \% \text { of } \\
\text { predicted value }\end{array}$ & $38.0(28.0-51.0)$ & $43.5(32.0-57.0)$ & 0.063 & $42.5(29.5-52.0)$ & $43.5(32.0-57.0)$ & 0.410 \\
\hline mMRC dyspnea score" $(0 / 1 / 2 / 3 / 4), \%$ & $7 / 21 / 27 / 23 / 20$ & $3 / 23 / 26 / 34 / 12$ & 0.302 & $8 / 17 / 30 / 31 / 14$ & $3 / 23 / 27 / 34 / 13$ & 0.705 \\
\hline Body mass index, $\mathrm{kg} / \mathrm{m}^{2 \mathrm{~s}}$ & $22.0 \pm 4.0$ & $22.8 \pm 4.2$ & 0.168 & $22.2 \pm 3.9$ & $22.8 \pm 4.2$ & 0.414 \\
\hline $\begin{array}{l}\text { History of hospitalization due to } \\
\text { COPD exacerbation in the previous } \\
\text { year, } \mathrm{n}(\%)^{\S}\end{array}$ & $33(24.0)$ & $15(23.4)$ & $>0.999$ & $12(18.8)$ & $15(23.4)$ & 0.665 \\
\hline Charlson comorbidity index & $4(4-5)$ & $4(4-6)$ & 0.365 & $5(4-6)$ & $4(4-6)$ & 0.600 \\
\hline \multicolumn{7}{|l|}{ Disease, n (\%) } \\
\hline Myocardial infarction & $8(5.8)$ & $9(14.0)$ & 0.059 & $3(4.7)$ & $9(14.1)$ & 0.129 \\
\hline Congestive heart failure & $24(17.4)$ & $17(26.5)$ & 0.137 & $16(25.0)$ & $17(26.6)$ & 0.999 \\
\hline Peripheral disease & $2(1.4)$ & $4(6.2)$ & 0.081 & $2(3.1)$ & $4(6.3)$ & 0.676 \\
\hline Cerebrovascular disease & $3(2.2)$ & $3(4.9)$ & 0.384 & $1(1.6)$ & $3(4.7)$ & 0.611 \\
\hline Liver disease & $4(2.9)$ & $2(3.1)$ & 0.999 & $3(4.7)$ & $2(3.1)$ & 0.999 \\
\hline Diabetes & $21(15.2)$ & $8(12.5)$ & 0.672 & $7(10.9)$ & $8(12.5)$ & 0.999 \\
\hline Moderate or severe renal disease & $9(6.5)$ & $4(6.2)$ & 0.999 & $5(10.9)$ & $4(6.3)$ & 0.999 \\
\hline Malignancy & $17(12.3)$ & $11(17.2)$ & 0.518 & $12(18.8)$ & $11(17.2)$ & 0.999 \\
\hline Increased sputum, \% & $95(68.8)$ & $39(60.9)$ & 0.344 & $38(59.4)$ & $39(60.9)$ & 0.999 \\
\hline Purulent sputum, $\%$ & $53(38.4)$ & $19(29.7)$ & 0.296 & $22(34.4)$ & $19(29.7)$ & 0.705 \\
\hline \multicolumn{7}{|l|}{ ABGA } \\
\hline $\mathrm{pO}_{2}, \mathrm{~mm} \mathrm{Hg}^{\S}$ & $58.5(47.0-72.0)$ & $62.0(47.0-71.1)$ & 0.823 & $60.0(49.0-72.0)$ & $62.0(47.0-71.1)$ & 0.924 \\
\hline $\mathrm{pCO}_{2}, \mathrm{~mm} \mathrm{Hg}^{\S}$ & $44.0(36.0-62.0)$ & $41.0(36.5-47.5)$ & 0.224 & $41.0(35.0-50.0)$ & $41.0(36.5-47.5)$ & 0.859 \\
\hline $\mathrm{SpO}_{2}, \%^{\S}$ & $91.0(82.0-95.0)$ & $91.0(85.0-95.0)$ & 0.904 & $91.0(83.0-95.0)$ & $91.0(85.0-95.0)$ & 0.881 \\
\hline Oxygen supply, $\mathrm{FiO}_{2}, \%$ & $28.0(20.0-36.0)$ & $28.0(20.0-30.0)$ & 0.243 & $27.0(20.0-30.0)$ & $28.0(20.0-30.0)$ & 0.649 \\
\hline
\end{tabular}

*Matched group: after propensity score matching, CT group and non-CT group was matched with baseline characteristics. The following variables were matched; sex, age, smoking status, Charlson comorbidity index, mMRC dyspnea scale, FEV $\mathrm{F}_{1}$, initial concentration of O2 supply. 'Non-CT group: patients with COPD exacerbation but didn't performed chest CT. ${ }^{*}$ CT group: patients with COPD exacerbation and per-

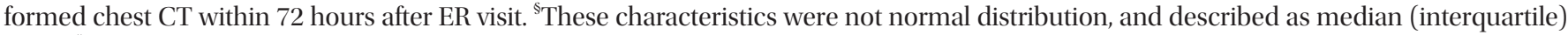
scale. "The data of these characteristics were at the time in stable state of the COPD patients before hospitalization. "Charlson comorbidity index predict one-year mortality for patients who have comorbid conditions, such as heart disease, cancer, diabetes mellitus. Each condition is assigned a score of $1,2,3$, or 6 , depending on the risk of dying associated with each one.

pertension by echocardiography. Table 2 represents that chest CT was helpful in finding the cause of COPD exacerbation by characterizing the lesion.

\section{Chest CT and clinical outcomes}

We found no differences regarding the three clinical out- comes between the non-CT and CT groups for: the median length of hospital stay in days (range) (8 [6-13] vs. 8 [6-12] days, $\mathrm{p}=0.786$ ); ICU care (14 patients [10.1\%] vs. 11 patients [16.7\%], $\mathrm{p}=0.236$ ); hospital death ( 1 [1.4\%] vs. 1 [1.5\%], $\mathrm{p} \geq 0.999)$ were represented Table 3.

Additionally, we compared treatment courses of two group. Treatment courses as duration of antibiotics, steroid, nebuliz- 
Table 2. Changed or additional diagnosis and treatment after chest CT

\begin{tabular}{|ccl|}
\hline Diagnosis & No. of patients & \multicolumn{1}{c|}{ Treatment } \\
\hline Changed diagnosis & $2 / 64^{*}$ & Changed treatment accordingly \\
\hline Pulmonary embolism & 1 & Anticoagulation \\
\hline Lung cancer progression & 1 & No treatment change \\
\hline Additional diagnosis & $27 / 64$ & Additional examination or treatment \\
\hline Pneumonia (small extents) & $21^{\dagger}$ & Antibiotics in 4 patients, stop steroid in 1 patient \\
\hline Lung nodule & 2 & PCNBx/follow up chest $\mathrm{CT}^{+}$ \\
\hline Small amount pleural effusion & 1 & Diuretics use \\
\hline Pericardial effusion & 1 & Follow up echocardiography \\
\hline Pulmonary edema & 1 & Observation \\
\hline Pulmonary hypertension & 1 & Sildenafil \\
\hline
\end{tabular}

*After computed tomography (CT) diagnosis was changed in two patients out of 64 patients who performed CT. ${ }^{\dagger} 17$ out of 21 patients already used antibiotics before CT was performed; to only 4 patients, antibiotics was added. ${ }^{*}$ One patient with lung nodule performed percutaneous needle biopsy for lung nodule and squamous cell carcinoma was diagnosed but no further treatment for poor performance status. The other patient with lung nodule was examined 6 months later, and the lung nodule disappeared at follow up chest CT.

Table 3. Clinical outcomes according to CT group vs. non-CT group

\begin{tabular}{|c|c|c|c|c|c|c|}
\hline & \multicolumn{3}{|c|}{ Unmatched group } & \multicolumn{3}{|c|}{ Matched group } \\
\hline & $\begin{array}{l}\text { Non-CT group } \\
\quad(n=138)\end{array}$ & $\begin{array}{c}\text { CT group } \\
(n=64)\end{array}$ & p-value & $\begin{array}{l}\text { Non-CT group } \\
\quad(n=64)\end{array}$ & $\begin{array}{c}\text { CT group } \\
(n=64)\end{array}$ & p-value \\
\hline \multicolumn{7}{|l|}{ Primary outcome } \\
\hline Length of hospital stay, day & $8(6.0-13.0)$ & $8(6.0-12.0)$ & 0.786 & $8(6.0-11.0)$ & $8(6.0-12.0)$ & 0.340 \\
\hline Hospital death, n (\%) & $1(1.4)$ & $1(1.5)$ & 0.999 & $0(0)$ & $1(1.6)$ & 0.999 \\
\hline \multicolumn{7}{|l|}{ Secondary outcome } \\
\hline ICU care, n (\%) & $14(10.1)$ & $11(16.7)$ & 0.236 & $4(6.2)$ & $11(17.2)$ & 0.099 \\
\hline ICU stay, day & $2.0(1.0-4.0)$ & $3.0(1.0-4.0)$ & 0.978 & $3.0(2.0-4.0)$ & $3.0(1.0-4.0)$ & 0.735 \\
\hline
\end{tabular}

Matching variables were selected through a multivariate regression model of ICU care and hospital stay: sex, age, smoking status, Charlson comorbidity index, purulent sputum, history of hospitalization due to COPD exacerbation in the previous year, $\mathrm{mMRC}_{\mathrm{M}} \mathrm{dyspnea} \mathrm{scale,} \mathrm{FEV}_{1} \%$, and initial concentration of $\mathrm{O}_{2}$ supply.

CT: computed tomography; ICU: intensive care unit; COPD: chronic obstructive pulmonary disease; mMRC: modified Medical Round Council Dyspnea Scale; $\mathrm{FEV}_{1}$ : forced expiratory volume in 1 second.

er showed no difference in two groups (Supplementary Table S2).

The multivariate analysis revealed that the length of hospital stay was increased as if male, high initial concentration of $\mathrm{O}_{2}$ supply or purulent sputum at admission, high mMRC dyspnea score in the stable state and past hospitalization within 1 year due to COPD exacerbation. But Table 4 represents that chest CT does not affect the length of hospital stay in patients with COPD exacerbation.

\section{Complications of contrast-enhanced chest CT}

In this study, 40 patients performed contrast-enhanced CT. Contrast induced nephropathy were founded in five patients (12.5\%) among the patients; however, all of the five patients recovered in a follow-up year. We used definition of contrast induced nephropathy as a $25 \%$ relative increase, or a $0.5 \mathrm{mg} /$ dL absolute increase, in serum creatinine within 72 hours of contrast exposure. There were no other complications such as agitation, red skin, and hypersensitivity to contrast media or any side effect wihin the patients.

\section{Propensity score matching}

The baseline $\mathrm{FEV}_{1}$ differed between the non-CT and CT groups, and some other variables were mismatched. Some variables might influence clinical outcomes such as hospital stay. Thus, the patients were matched based on the logit of the propensity score. Matching variables were followed; sex, age, smoking status, Charlson comorbidity index, purulent 
Table 4. Length of hospital stay and performance of CT were not related significantly

\begin{tabular}{|lcccc|}
\hline & $\beta \pm$ standard error & Standardized $\beta$ & Partial R & p-value \\
\hline Sex (male/female) & $-2.050 \pm 1.149$ & -0.115 & -0.127 & 0.076 \\
$\mathrm{FiO}_{2}, \%$ & $0.109 \pm 0.030$ & 0.239 & 0.250 & 0.001 \\
mMRC & $1.054 \pm 0.357$ & 0.194 & 0.207 & 0.004 \\
Past hospitalization within 1 year & $2.697 \pm 0.968$ & 0.181 & 0.196 & 0.006 \\
Purulent sputum & $-1.642 \pm 0.862$ & -0.124 & -0.135 \\
CT scan & $0.525 \pm 0.887$ & 0.039 & 0.042 & 0.554 \\
\hline
\end{tabular}

Multiple linear regression analysis was performed with an adjustment of covariates; age, sex, $\mathrm{FEV}_{1}$, initial concentration of $\mathrm{O}_{2}$ supply, smoking, charlson comorbidity index, body mass index, history of hospitalization due to COPD exacerbation in the previous year, baseline mMRC dyspnea scale, increased or purulent sputum, initial $\mathrm{pO}_{2}, \mathrm{pCO}_{2}$ results.

CT: computed tomography; $\beta$ : regression coefficient; $\mathrm{FiO}_{2}$ : fraction of inspired oxygen; mMRC: modified Medical Research Council Dyspnea Scale; $\mathrm{FEV}_{1}$ : forced expiratory volume in 1 second; $\mathrm{COPD}$ : chronic obstructive pulmonary disease; $\mathrm{pO}_{2}$ : partial pressure of oxygen; $\mathrm{pCO}_{2}$ : partial pressure of carbon dioxide.

sputum, history of hospitalization due to COPD exacerbation in the previous year, mMRC dyspnea scale, $\mathrm{FEV}_{1} \%$, and initial concentration of $\mathrm{O}_{2}$ supply.

After matching, 64 patients were selected from each group. Hospital stay and ICU care were compared between the two groups. However, there were no differences between the non-CT and CT groups for the following: length of hospital stay (days) (8 days [interquartile range, 6.0-11.0] vs. 8 days [6.0-12.0], $\mathrm{p}=0.340$ ); ICU care (4 patients [6.2\%] vs. 11 patients [17.2\%], p=0.099); hospital death (0 [0.0\%] vs. 1 [1.6\%], $\mathrm{p}=0.999)$.

\section{Discussion}

In the present study, CT was helpful for a changed and additional diagnosis in patients hospitalized with an initial diagnosis of a COPD exacerbation, but its use did not appear to affect the clinical outcomes.

Previously, physicians have increased the number of chest CT performed on patients with COPD exacerbation. CT scans are perpetuated even on those with no definite chest X-ray infiltration or other abnormalities. Some studies demonstrated the ability of CT scan to identify the main pathological changes of a COPD exacerbation, including emphysema, airway wall thickening, and reduced lumen caliber ${ }^{7,8}$. A pilot study reported that the non-enhanced chest CT exhibited bronchial infiltration in $61.5 \%$ of COPD patients during an exacerbation? However, the previous studies did not focus on the changed or additional diagnoses of COPD exacerbation. They had focused on the changes in the image of the COPD exacerbation itself. To the best of our knowledge, this is the first study to provide the evidence with supports the role of CT in regards to other possible diagnoses that should be considered in COPD exacerbation patients.

We found that chest CT changed the diagnoses in two of 64 patients and identified additional diagnoses 27 patients. However, there was no difference in clinical outcomes between the two groups, possibly because the treatment was changed in only $10.9 \%$ of the CT group. Although the most common additional diagnoses were pneumonia, $81 \%$ of patients had already been started with antibiotics before the CT; also, those who received antibiotics after the CT presented with relatively milder symptoms or signs of infection: mild or no fever, no purulent sputum, or low serum level of C-reactive protein. The treatment remained unchanged within patients with a lung nodule, pericardial effusion, or pulmonary edema.

Respiratory infections trigger approximately $70 \%$ of COPD exacerbations ${ }^{10}$. Pulmonary infiltration on the CT scan was found within one-third of the patients in the CT group, in accordance with the evidence indicating that infection may be a triggering factor in patients with no definite chest X-ray infiltration. In a recent study, patients with clinically suspected community-acquired pneumonia underwent a chest CT, which revealed parenchymal infiltration in $33 \%$ of the patients without infiltration via chest $\mathrm{X}$-ray ${ }^{4}$. This suggests that in patients suspected of having a community-acquired pneumonia, a chest CT could lead to a change of treatment. In the present study, however, most of the patients with the pneumonic infiltration continued corticosteroid. Because it was small extent of pneumonic infiltration that clinicians thought the risk of infection was not high enough to consider steroid-induced immunosuppression.

In the present study, 40 patients underwent contrastenhanced CT, and one patient (2.5\%) was diagnosed with a pulmonary embolism. In literature reviews, the prevalence of pulmonary embolism in patients admitted for an acute COPD exacerbation ranged from $3 \%$ to $20 \%^{11-13}$. In a Korean study, the prevalence of a pulmonary embolism in cases of COPD exacerbation was $5 \%^{14}$, suggesting a relatively low prevalence of pulmonary embolism in Korea ${ }^{11-13,15,16}$. In this study, we also found a low prevalence of pulmonary embolism. This may not 
significantly affect the diagnostic change and clinical outcome in patients with contrast-enhanced chest CT.

In the present study, we found a contrast-induced nephropathy in five patients among the 40 patients who performed contrast-enhanced CT. These finding may reflect that the risk of contrast induced nephropathy is greather than the benefit from contrast enhanced chest CT in patients with acute exacerbation of COPD.

In the present study, the clinical outcomes of COPD exacerbation exhibited risk factors or predictive factors similar to other studies ${ }^{17-19}$. Current smokers were less likely to be admitted to the ICU than ex-smokers or non-smokers. As a supporting evidence, in an Australian study of COPD exacerbation, exsmokers exhibited a longer length of hospital stay than current smokers $^{20}$.

Lung function, represented by $\mathrm{FEV}_{1}$, appeared not to be related to clinical outcomes when corrected with covariates in this study, even after propensity score matching. In a Greek report, lower $\mathrm{FEV}_{1}$ values were associated with a longer hospital stay in patients with COPD exacerbation ${ }^{19}$. In contrast, in a study by Soltani et al. ${ }^{20}, \mathrm{FEV}_{1}$ was not related to the hospital mortality and length of the hospital stay. Thus, lung function should be studied further in order to determine whether it is a significant factor for clinical outcomes in patients with COPD exacerbation.

There are a few additional limitations to note. First, it may have a selection bias as it is a retrospective study. Chest CT could be performed in patients who were clinically less respiratory infection symptoms or whose initial symptoms were not explained by COPD exacerbation. To overcome the bias, we have performed propensity score matching to evaluate clinically similar patients in COPD exacerbation. This means that design of study did not affect the outcome. Second, chest CT scans were not interpreted by a single radiologist, but by eight different radiologists; which may have led to inadequate conclusions. However, this study reflects the conditions in the actual clinical practice. and it is unlikely that it will be difficult for radiologists to detect for such diseases; pneumonia, lung nodules, lung cancer progression, pericardial effusion, pleural effusion.

Third, contrast enhanced CT was performed for $31 \%$ patients in the CT group, indicating that protocol of chest CT might cause change in diagnosis and clinical outcomes. In the case of a pulmonary embolism, it is only checked within enhanced chest CT. If an unnoticed pulmonary embolism or other disease is in non-enhance CT group, it can affect clinical outcomes. In sub-analysis group, we compared the results between non-CT group and contrast-enhanced CT group. And there was no significant difference between two group (Supplementary Tables S3, S4). Fourth, the reason why a physician performed a CT in this study was not obtained because most the reason was not described accurately in medical charts. All physicians might not have the same indication with which
CTs were performed in the COPD patients at emergency department. Some physicians might have reasonable indications, and other physicians might have vague indications. However, this study could reflect actual practice of performing chest CT in patients with COPD exacerbation.

Utility of CT in patient with acute COPD exacerbation might not be beneficial, and the present study did not provide enough rational evidence to recommend chest CT scan as a routine initial diagnostic tool.

\section{Authors' Contributions}

Conceptualization: Oh YM. Methodology: Park HJ, Oh YM. Formal analysis: Park HJ, Kim SH, Kim HC. Data curation: Park HJ, Kim HC. Validation: Seo JB, Lee BY, Lee SW, Lee JS, Lee SD. Writing - original draft preparation: Park HJ, Kim SH. Writing - review and editing: Park HJ, Oh YM. Approval of final manuscript: all authors.

\section{Conflicts of Interest}

No potential conflict of interest relevant to this article was reported.

\section{Acknowledgments}

This study was supported by Obstructive Lung Disease Research Foundation, Seoul, Korea (www.oldrf.org/En/HOME/).

\section{Supplementary Material}

Supplementary material can be found in the journal homepage (https://e-trd.org/).

Supplementary Table S1. Bronchodilator response in CT vs. non-CT group

Supplementary Table S2. The duration of drugs use for acute exacerbation of COPD.

Supplementary Table S3. Baseline characteristics of non-CT group and contrast enhanced CT group.

Supplementary Table S4. Clinical outcomes according to contrast enhanced CT group vs. non-CT group.

\section{References}

1. Global Initiative for Chronic Obstructive Lung Disease. Global strategy for the diagnosis, management and prevention of COPD. Global Initiative for Chronic Obstructive Lung Disease (GOLD); 2016. p. 111. 
2. Abudagga A, Sun SX, Tan H, Solem CT. Exacerbations among chronic bronchitis patients treated with maintenance medications from a US managed care population: an administrative claims data analysis. Int J Chron Obstruct Pulmon Dis 2013;8:175-85.

3. Dixit D, Bridgeman MB, Andrews LB, Narayanan N, Radbel J, Parikh A, et al. Acute exacerbations of chronic obstructive pulmonary disease: diagnosis, management, and prevention in critically ill patients. Pharmacotherapy 2015;35:631-48.

4. Claessens YE, Debray MP, Tubach F, Brun AL, Rammaert B, Hausfater P, et al. Early chest computed tomography scan to assist diagnosis and guide treatment decision for suspected community-acquired pneumonia. Am J Respir Crit Care Med 2015;192:974-82.

5. Cardinale L, Priola AM, Moretti F, Volpicelli G. Effectiveness of chest radiography, lung ultrasound and thoracic computed tomography in the diagnosis of congestive heart failure. World J Radiol 2014;6:230-7.

6. Nagarsheth K, Kurek S. Ultrasound detection of pneumothorax compared with chest X-ray and computed tomography scan. Am Surg 2011;77:480-4.

7. Cheng T, Wan HY, Cheng QJ, Guo Y, Qian YR, Fan L, et al. Obvious emphysema on computed tomography during an acute exacerbation of chronic obstructive pulmonary disease predicts a poor prognosis. Intern Med J 2015;45:517-26.

8. Hackx M, Ghaye B, Coche E, Muylem AV, Gevenois PA. Severe COPD exacerbation: CT features. COPD 2015;12:38-45.

9. Cheng T, Wan H, Cheng Q, Guo YI, Qian Y, Fan L, et al. Computed tomography manifestation of acute exacerbation of chronic obstructive pulmonary disease: a pilot study. Exp Ther Med 2016;11:519-29.

10. Sogaard M, Madsen M, Lokke A, Hilberg O, Sorensen HT, Thomsen RW. Incidence and outcomes of patients hospitalized with COPD exacerbation with and without pneumonia. Int J Chron Obstruct Pulmon Dis 2016;1 1:455-65.

11. Shapira-Rootman M, Beckerman M, Soimu U, Nachtigal A, Zeina AR. The prevalence of pulmonary embolism among patients suffering from acute exacerbations of chronic obstructive pulmonary disease. Emerg Radiol 2015;22:257-60.
12. Rizkallah J, Man SFP, Sin DD. Prevalence of pulmonary embolism in acute exacerbations of COPD: a systematic review and metaanalysis. Chest 2009;135:786-93.

13. Rutschmann OT, Cornuz J, Poletti PA, Bridevaux PO, Hugli OW, Qanadli SD, et al. Should pulmonary embolism be suspected in exacerbation of chronic obstructive pulmonary disease? Thorax 2007;62:121-5.

14. Choi KJ, Cha SI, Shin KM, Lee J, Hwangbo Y, Yoo SS, et al. Prevalence and predictors of pulmonary embolism in Korean patients with exacerbation of chronic obstructive pulmonary disease. Respiration 2013;85:203-9.

15. Hartmann IJ, Hagen PJ, Melissant CF, Postmus PE, Prins MH. Diagnosing acute pulmonary embolism: effect of chronic obstructive pulmonary disease on the performance of D-dimer testing, ventilation/perfusion scintigraphy, spiral computed tomographic angiography, and conventional angiography. ANTELOPE Study Group. Advances in New Technologies Evaluating the Localization of Pulmonary Embolism. Am J Respir Crit Care Med 2000;162:2232-7.

16. Akpinar EE, Hosgun D, Doganay B, Atac GK, Gulhan M. Should the cut-off value of $\mathrm{D}$-dimer be elevated to exclude pulmonary embolism in acute exacerbation of COPD? J Thorac Dis 2013;5:430-4.

17. Garcia-Sanz MT, Canive-Gomez JC, Garcia-Couceiro N, Senin-Rial L, Alonso-Acuna S, Barreiro-Garcia A, et al. Factors associated with the incidence of serious adverse events in patients admitted with COPD acute exacerbation. Ir J Med Sci 2017;186:477-83.

18. Ramaraju K, Kaza AM, Balasubramanian N, Chandrasekaran S. Predicting healthcare utilization by patients admitted for COPD exacerbation. J Clin Diagn Res 2016;10:OC13-7.

19. Diamantea F, Kostikas K, Bartziokas K, Karakontaki F, Tsikrika S, Pouriki S, et al. Prediction of hospitalization stay in COPD exacerbations: the AECOPD-F score. Respir Care 2014;59:1679-86.

20. Soltani A, Reid D, Wills K, Walters EH. Prospective outcomes in patients with acute exacerbations of chronic obstructive pulmonary disease presenting to hospital: a generalisable clinical audit. Intern Med J 2015;45:925-33. 
Supplementary Table S1. Bronchodilator response in CT vs. non-CT group

\begin{tabular}{|c|c|c|c|}
\hline Bronchodilator response & Non-CT group $(n=138)$ & CT group $(n=64)$ & p-value \\
\hline Negative & $120(87)$ & $57(89)$ & 0.482 \\
\hline Positive & $8(5.8)$ & $4(6.3)$ & \\
\hline
\end{tabular}

Values are presented as number (\%).

CT: computed tomography. 
Supplementary Table S2. The duration of drugs use for acute exacerbation of COPD

\begin{tabular}{|lccc|}
\hline & Non-CT group $(\mathbf{n}=\mathbf{1 3 8})$ & CT group $(\mathbf{n}=\mathbf{6 4})$ & p-value \\
\hline Antibiotics day & $10.5(5.8-14.3)$ & $11(6-14)$ & 0.864 \\
\hline Use of antibiotics, $\%$ & 88.4 & 81.3 & 0.250 \\
\hline Steroid use day & $7.5(0-14)$ & $7(0-13)$ & 0.560 \\
\hline Use of steroid, \% & 73.1 & 70.3 & 0.798 \\
\hline Nebulizer day & $5(3-10)$ & $6(3-9)$ & 0.824 \\
\hline Use of nebulizer, \% & 89.9 & 85.9 & 0.564 \\
\hline
\end{tabular}

COPD: chronic obstructive pulmonary disease; CT: computed tomography. 
Supplementary Table S3. Baseline characteristics of non-CT group and contrast enhanced CT group

\begin{tabular}{|c|c|c|c|c|c|c|}
\hline \multirow[b]{2}{*}{ Characteristic } & \multicolumn{3}{|c|}{ Unmatched group } & \multicolumn{3}{|c|}{ Matched group } \\
\hline & $\begin{array}{l}\text { Non-CT group } \\
\quad(n=138)\end{array}$ & $\begin{array}{c}\text { CT group } \\
(n=40)\end{array}$ & p-value & $\begin{array}{l}\text { Non-CT group } \\
(n=40)\end{array}$ & $\begin{array}{c}\text { CT-group } \\
(n=40)\end{array}$ & p-value \\
\hline Mean age, yr & $72.0(67.0-76.0)$ & $73.0(67.0-78.0)$ & 0.409 & $72.5(68.5-78.0)$ & $73.0(67.0-78.0)$ & 0.874 \\
\hline $\begin{array}{l}\text { Smoking status } \\
\text { Never/Ex-smoker/current, \% }\end{array}$ & $23 / 56 / 21$ & $28 / 52 / 20$ & 0.854 & $23 / 60 / 17$ & $28 / 52 / 20$ & 0.792 \\
\hline mMRC dyspnea score $(0 / 1 / 2 / 3 / 4), \%$ & $7 / 21 / 27 / 23 / 20$ & $5 / 30 / 23 / 30 / 12$ & 0.554 & $10 / 18 / 40 / 15 / 17$ & $5 / 30 / 23 / 30 / 12$ & 0.179 \\
\hline Body mass index, $\mathrm{kg} / \mathrm{m}^{2}$ & $22.0 \pm 4.0$ & $23.0 \pm 4.2$ & 0.138 & $23.4 \pm 4.3$ & $23.0 \pm 4.2$ & 0.700 \\
\hline $\begin{array}{l}\text { History of hospitalization due to } \\
\text { COPD exacerbation in the previous } \\
\text { year, } \mathrm{n}(\%)\end{array}$ & $33(23.9)$ & $7(17.5)$ & 0.522 & $8(20.0)$ & $7(17.5)$ & 0.999 \\
\hline Myocardial infarction & $8(5.8)$ & $6(15.0)$ & 0.116 & $3(7.5)$ & $6(15.0)$ & 0.479 \\
\hline Congestive heart failure & $24(17.4)$ & $11(27.5)$ & 0.234 & $8(20.0)$ & $11(27.5)$ & 0.599 \\
\hline Peripheral disease & $2(1.4)$ & $2(5.0)$ & 0.466 & $1(2.5)$ & $2(5.0)$ & 0.999 \\
\hline Cerebral artery disease & $3(2.2)$ & $1(2.5)$ & 0.999 & $1(2.5)$ & $1(2.5)$ & 0.999 \\
\hline Diabetes mellitus & $21(15.2)$ & $3(7.5)$ & 0.320 & $5(12.5)$ & $3(7.5)$ & 0.709 \\
\hline Renal disease & $9(6.5)$ & $1(2.5)$ & 0.999 & $3(7.5)$ & $1(2.5)$ & 0.608 \\
\hline Liver disease & $4(2.9)$ & $1(2.5)$ & 0.999 & $1(2.5)$ & $1(2.5)$ & 0.999 \\
\hline Increased sputum & $95(68.8)$ & $22(55.0)$ & 0.151 & $22(55.0)$ & $22(55.0)$ & 0.999 \\
\hline
\end{tabular}

CT: computed tomography; $\mathrm{FEV}_{1}$ : forced expiratory volume in 1 second; mMRC: modified Medical Round Council Dyspnea Scale; COPD: chronic obstructive pulmonary disease; $\mathrm{ABGA}$ : arterial blood gas analysis; $\mathrm{pO}_{2}$ : partial pressure of oxygen; $\mathrm{pCO}_{2}$ : partial pressure of carbon dioxide; $\mathrm{SpO}_{2}$ : oxygen saturation; $\mathrm{FiO}_{2}$ : fraction of inspired oxygen. 
Supplementary Table S4. Clinical outcomes according to contrast enhanced CT group vs. non-CT group

\begin{tabular}{|c|c|c|c|c|c|c|}
\hline & \multicolumn{3}{|c|}{ Unmatched group } & \multicolumn{3}{|c|}{ Matched group } \\
\hline & $\begin{array}{l}\text { Non-CT group } \\
\quad(n=138)\end{array}$ & $\begin{array}{c}\text { CT group } \\
(n=40)\end{array}$ & p-value & $\begin{array}{l}\text { Non-CT group } \\
\quad(n=40)\end{array}$ & $\begin{array}{l}\text { CT group } \\
(n=40)\end{array}$ & p-value \\
\hline \multicolumn{7}{|l|}{ Primary outcome } \\
\hline Length of hospital stay, day & $8.0(6.0-13.0)$ & $8.0(6.0-11.5)$ & 0.887 & $8.0(5.0-12.5)$ & $8.0(6.0-11.5)$ & 0.616 \\
\hline Hospital death, n (\%) & $1(0.7)$ & $1(2.5)$ & 0.931 & $0(0)$ & $1(2.5)$ & 0.999 \\
\hline \multicolumn{7}{|l|}{ Secondary outcome } \\
\hline ICU care, n (\%) & $14(10.1)$ & $7(17.5)$ & 0.321 & $3(7.5)$ & $7(17.5)$ & 0.310 \\
\hline ICU stay, day & $2.0(1.0-4.0)$ & $1.0(1.0-4.5)$ & 0.759 & $2.0(2.0-3.0)$ & $1.0(1.0-4.5)$ & 0.723 \\
\hline
\end{tabular}

CT: computed tomography; ICU: intensive care unit. 